\title{
Ten principles relevant to health research among Indigenous Australian populations
}

\section{Working with Indigenous communities towards research that is relevant, effective and culturally respectful}

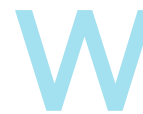

riting in the Journal about Indigenous health in 2011, Sir Michael Marmot suggested that

the challenge was to conduct research, and to ultimately apply findings from that research, to enable Indigenous Australians to lead more flourishing lives that they would have reason to value. ${ }^{1}$ As committed Indigenous health researchers in Australia, we reflect Marmot's ideal — to provide the answers to key questions relating to health that might enable Indigenous Australians to live the lives that they would choose to live.

As a group, we have over 120 collective years' experience in Indigenous health research. Over this time, particularly in recent years as ethical guidelines have come into play, there have been many examples of research done well. However, as the pool of researchers is constantly replenished, we hold persisting concerns that some emerging researchers may not be well versed in the principles of best practice regarding research among Indigenous Australian populations.

Implementing any research methodology among Indigenous Australian groups will work best when the following 10 principles are met. These principles are reflected in the many documents related to working and researching with Indigenous Australians; for example, the National Health and Medical Research Council (NHMRC) ethical guidelines for research among Aboriginal and Torres Strait Islander people. ${ }^{2}$ In this article, we set out these principles in one short, accessible document.

\section{Essential principles}

\section{Addressing a priority health issue as determined by the community}

No group is more aware of the health inequalities between Indigenous and non-Indigenous Australians than Indigenous Australians themselves. Researchers need to work in close partnership with the community so that their own objectives and ideas do not mask the community's own priority areas. ${ }^{3}$ This will require both parties to learn how to work together to manage potentially conflicting agendas, including differences in priority perceptions, community politics and interpretation of findings. The communities and participants need to be engaged as equal partners in all phases of the research process, with a flexible agenda responsive to broader environmental demands.

\section{Conducting research within a mutually respectful partnership framework}

An open and transparent relationship with key community groups is critical to the success of implementing research projects among Indigenous Australians. This can be neither rushed nor faked. Indigenous communities are more likely to embrace working with researchers with whom they have an established rapport than with someone unfamiliar, regardless of the eminence of the researchers, sophistication of the study design or amount of funding available. Researchers should ideally have a commitment to continuing to work with a given Indigenous group (especially if reasonably secure employment opportunities might be possible) following cessation of the study.

In addition, within any given community it is vital to identify key champions for the study and those who are likely to block access. The team of champions might take months or years to foster but their involvement will make an enormous difference in people's willingness to enrol in and continue with the study. We have learnt (sometimes the hard way) the importance of understanding the local "lay of the land" in terms of governance and in working hard to foster open and trusting relationships with those whose support the study's success will rely on. Professor

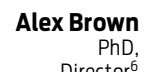
Director ${ }^{6}$

1 University of Adelaide, Adelaide, SA.

2 University of Melbourne, Melbourne, VIC.

3 Baker IDI Heart and Diabetes Institute, Melbourne, VIC.

4 Menzies School of Health Research, Darwin, NT.

5 George Institute, Sydney, NSW.

6 Baker IDI Heart and Diabetes Institute, Alice Springs, NT.

lisa.jamieson@ adelaide.edu.au

doi: 10.5694/mjall.11642

\section{Capacity building is a key focus of the research partnership, with sufficient budget to support this}

Investigators must have a commitment to employ Indigenous staff and provide opportunities for such staff to continue and develop their research careers if at all possible. As well as allowing capacity building of Indigenous staff, this will create substantial learning opportunities for non-Indigenous personnel. Different models of employing Indigenous staff may be required in different situations, and partnering with Aboriginalcontrolled health services can be critical. ${ }^{4}$

Many projects are underfunded. Personnel costs are high and staff turnover might be excessive, more time than anticipated might be required for community engagement, trips may need to be rescheduled, it may take much longer to recruit, and unforeseen circumstances (eg, cultural-based delays to the study) are almost certainly guaranteed. It can be difficult to achieve the desired sample size when undertaking research with Indigenous Australians. ${ }^{5}$ These issues are not unique to Australia, with other investigations involving indigenous populations internationally also having been abandoned due to recruiting difficulties. ${ }^{6-8}$ Researchers need to be realistic about these well documented difficulties when planning budgets. 


\section{Flexibility in study implementation while maintaining scientific rigour}

Flexible study implementation may relate to issues such as the need to adjust the planned geographic location, modify eligibility criteria while maintaining scientific rigour, or revise the study protocol based on community feedback. In the United States, many intervention studies among the Native American population have reported no effects, when in fact the lack of results stemmed from poor implementation of the intervention, rather than from shortcomings in the intervention itself. ${ }^{9}$ Researchers have suggested that future interventions should "place greater emphasis on the involvement of community members and organizational leaders in the development and implementation of interventions" and that a "community-based approach is key to sustainability and acceptability" ${ }^{10}$

\section{Respecting communities' past and present experience of research}

On one level, the history of Australia's Indigenous populations - involving forced policies of assimilation, imposed removal of children, profound and sustained social disadvantage, and dislocation from mainstream life — needs to be recognised. ${ }^{11}$ In the context of research, Indigenous Australians' past experience of involvement in research ${ }^{12}$ needs to be understood when conducting community consultation, in order to foster support and trust. Researchers also have to be ready for communities to say "no" at any point during a study. Finally, communities have a right to expect that if they agree to be involved in research, it will be of sufficiently high quality and rigour to generate meaningful results and change health outcomes.

\section{Desirable principles}

\section{Recognising the diversity of Indigenous Australian populations}

Although Australia's Indigenous population represents a small proportion of the total population $(2.6 \%$ in the 2006 Census $\left.^{13}\right)$, there is great heterogeneity among the many Indigenous groups. ${ }^{14}$ This diversity is not such an issue when studies are based within a localised geographic area (although even in small geographic areas the differences may be greater than appreciated ${ }^{15}$ ), but needs to be carefully planned for when implementing research (such as national population-level surveys) that may include many different language and culturally distinct groups. ${ }^{15}$

\section{Ensuring extended timelines do not jeopardise projects}

In our collective experience, timelines for conducting research with Australian Indigenous groups sometimes need to be extended. Reasons include delays in obtaining ethical approvals (many studies require formal approval from Aboriginal human research ethics committees, which frequently require written letters of support from key Indigenous stakeholder groups); delays and interruptions to community consultation sessions; delays to interviewing and employing local community members as staff; unforeseen community-based events (eg, funerals, community meetings, council or health service instability); the need for longer recruitment times; unforeseen weather events; and difficulties in securing appropriate travel and accommodation. In addition, the myriad demands placed on Indigenous communities and their members require research to "wait its turn". Projects that have run on time and within budget have usually taken account of these challenges in the planning stages.

\section{Preparing for Indigenous leadership turnover}

Leadership turnover among key Indigenous stakeholder groups can be high. ${ }^{16}$ This occurs at both high-end governance and grassroot community levels. There is enormous, often unreasonable, pressure placed on many Indigenous Australians in leadership, both from within their own communities and from mainstream structures. Non-Indigenous researchers would do well to anticipate this in advance rather than rely on a small number of key Indigenous leaders to promote and advocate their study. Indigenous advisory committees are invaluable in offering further advice on this issue, as are local Aboriginal ethics committees and community-controlled health organisations. Maintaining close and trusting relationships with a number of local Indigenous leaders (and recognising that these may take years to establish) may help researchers prepare for such occurrences.

\section{Supporting community ownership}

In the past, the rights, interests and concerns of Indigenous participants were frequently ignored by non-Indigenous researchers. ${ }^{17}$ We now know that the sustainability of research projects is achieved only when there has been substantive community input and ownership. ${ }^{18}$ From the outset, research projects need to be directed by the relevant Indigenous communities, by forming Indigenous advisory committees where possible, and by researchers constantly reviewing their study goals with these committees and Indigenous staff. While this is ideal, membership of advisory or steering committees can place a substantial burden and expectation on the relatively small number of people who have the time, interest and skills to sit on them. If it is not possible to form such a committee, the role of Indigenous staff and Indigenous community members becomes even more critical.

\section{Developing systems to facilitate partnership management in multicentre studies}

Investigations involving Indigenous Australians are becoming increasingly multicentre, both within Australia and with international collaborators. Ensuring that equitable and transparent processes are in place for managing partnerships, community engagement and recruitment, ethics, intervention implementation, use of new technologies, and compliance with privacy requirements is critical for the wellbeing of both study participants and the wider research community. 


\section{Conclusion}

These 10 principles should be considered from the initial design stage of the project, ideally when consulting with the community and writing funding applications. This may have policy implications for funding bodies, as substantially more funding will likely be necessary to ensure that specific principles can be followed - eg, regarding capacity building (3) and extended timelines (7). Application of the principles should not affect the accurate reporting of trials using tools such as the Consolidated Standard of Reporting Trials. The principles support, and could be considered in harmony with, existing NHMRC ethics guidelines. $^{2}$

Most of the principles have been reported before with respect to research involving marginalised peoples, ${ }^{19}$ Indigenous Australians, ${ }^{12}$ other indigenous peoples ${ }^{20}$ and the general population. ${ }^{21}$ They should also be seen in their broad context - we are only 10 among hundreds of researchers working with Indigenous populations in Australia. We believe that the 10 principles are relevant to all Indigenous health-related research. If considered, they may, in a small way, help research projects among Indigenous Australians be implemented in the most effective and culturally respectful way possible.

Acknowledgements: We gratefully acknowledge Sir Michael Marmot, University College London, who provided helpful comments on an earlier draft of this manuscript. Lisa Jamieson is supported by an NHMRC Career Development Award (605837), Louise Maple-Brown by an NHMRC Early Career Fellowship in Aboriginal and Torres Strait Islander Health Research (605837), Yin Paradies by a University of Melbourne McKenzie Fellowship, Ross Bailie by an Australian Research Council Future Fellowship (FT100100087), Alwin Chong by an NHMRC Senior Research Fellowship (457101) and Alex Brown by a Heart Foundation of Australia Fellowship.

Competing interests: No relevant disclosures.

Provenance: Not commissioned; externally peer reviewed.

1 Marmot M. Social determinants and the health of Indigenous Australians. Med J Aust 2011; 194: 512-513.

2 National Health and Medical Research Council. Values and ethics: guidelines for ethical conduct in Aboriginal and Torres Strait Islander health research Canberra: Commonwealth of Australia, 2003. http://www.nhmrc.gov.au/_ files_nhmrc/publications/attachments/e52.pdf (accessed Jun 2012).
3 Bailey J, Veitch C, Crossland L, Preston R. Developing research capacity building for Aboriginal and Torres Strait Islander health workers in health service settings. Rural Remote Health 2006; 6: 556.

4 Hughes J, Nickels M, Sharma S, et al. Implementing the eGFR study in a remote site: a case study. Aboriginal Islander Health Worker J 2010; 34: 6-8.

5 Sibthorpe BM, Bailie RS, Brady MA, et al. The demise of a planned randomised controlled trial in an urban Aboriginal medical service. Med J Aust 2002; 176: 273-276.

6 Riedy C. A dental intervention with an Alaskan Native population: lessons learned. Int Dent J 2010; 60: 241-244.

7 Patten CA, Windsor RA, Renner CC, et al. Feasibility of a tobacco cessation intervention for pregnant Alaska Native women. Nicotine Tob Res 2010; 12 : 79-87.

8 Chino M, Debruyn L. Building true capacity: indigenous models for indigenous communities. Am J Public Health 2006; 96: 596-599.

9 Gittelsohn J, Davis SM, Steckler A, et al. Pathways: lessons learned and future directions for school-based interventions among American Indians. Prev Med 2003; 37 Suppl 1: S107-S112.

10 Gittelsohn J, Rowan M. Preventing diabetes and obesity in American Indian communities: the potential of environmental interventions. Am J Clin Nutr 2011; 93: 1179S-1183S.

11 Altman J. The economic and social context of Indigenous health. In: Thomson $\mathrm{N}$, editor. The health of Indigenous Australians. Melbourne: Oxford University Press, 2003: 25-43.

12 Harvey PW. Science, research and social change in Indigenous health evolving ways of knowing. Aust Health Rev 2009; 33: 628-635.

13 Australian Bureau of Statistics. Population distribution, Aboriginal and Torres Strait Islander Australians, 2006. Canberra: ABS, 2007. (ABS Cat. No. 4705.0.)

14 McGregor R. Imagined destinies: Aboriginal Australians and the doomed race theory, 1880-1939. Melbourne: Melbourne University Press, 1997.

15 Nelson A, Abbott R, Macdonald D. Indigenous Australians and physical activity: using a social-ecological model to review the literature. Health Educ Res 2010; 25: 498-509.

16 Panaretto K, Coutts J, Johnson L, et al. Evaluating performance of and organisational capacity to deliver brief interventions in Aboriginal and Torres Strait Islander medical services. Aust N Z J Public Health 2010; 34: 38-44.

17 Couzos S, Lea T, Murray R, Culbong M. "We are not just participants - we are in charge": the NACCHO ear trial and the process for Aboriginal communitycontrolled health research. Ethn Health 2005; 10: 91-111.

18 Baeza Jl, Lewis JM. Indigenous health organizations in Australia: connections and capacity. Int J Health Serv 2010; 40: 719-742.

19 Smith $L$. How ethical is ethical research? Recruiting marginalized, vulnerable groups into health services research. J Adv Nurs 2008; 62: 248-257.

20 Flicker S, Worthington CA. Public health research involving aboriginal peoples: research ethics board stakeholders' reflections on ethics principles and research processes. Can J Public Health 2012; 103: 19-22.

21 Holland S, Hope T. The ethics of attaching research conditions to access to new health technologies. J Med Ethics 2012. In press. doi:10.1136/medethics-2011100294.

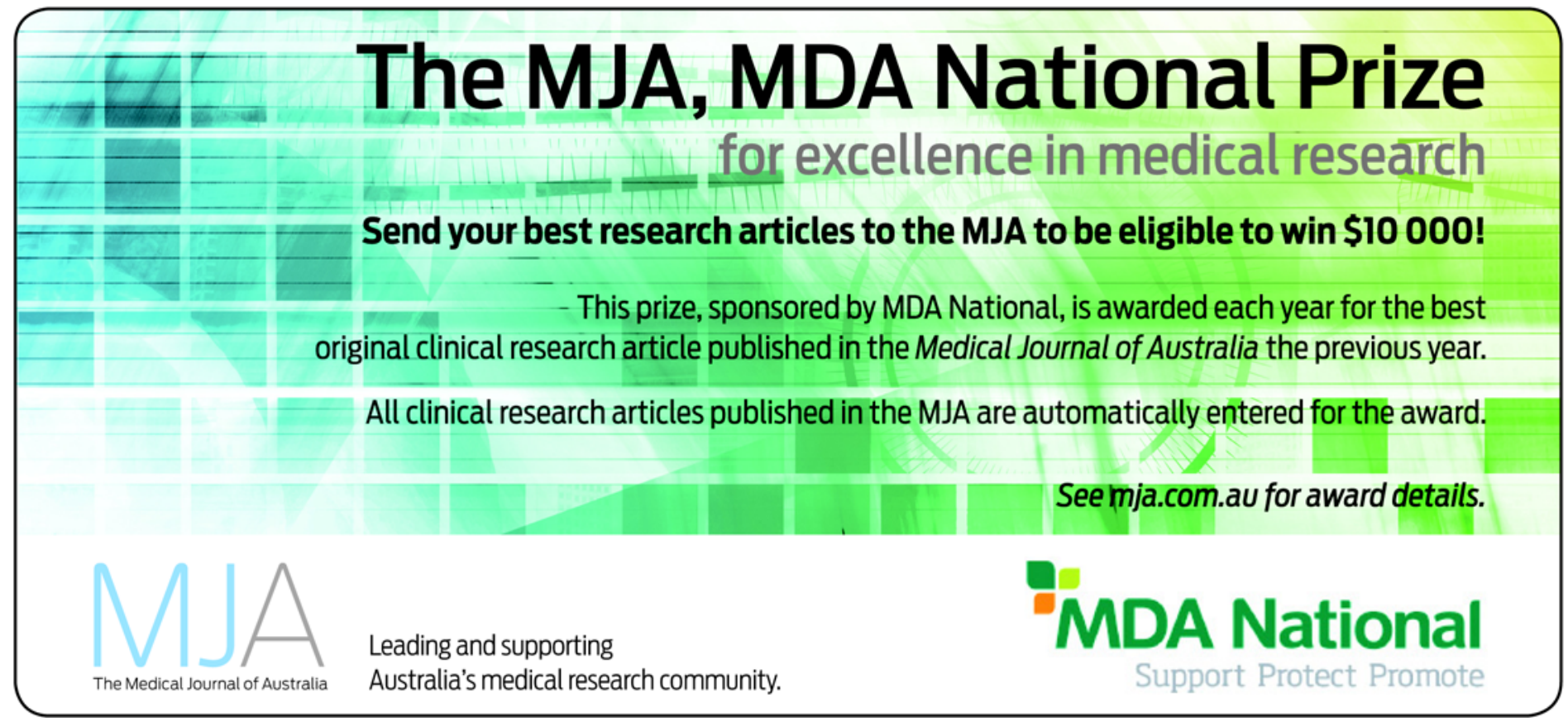

